\title{
Living with Manny's dangerous idea
}

\section{STEPHEN C. LEVINSON}

MAX PLANCK INSTITUTE FOR PSYCHOLINGUISTICS, NIJMEGEN, THE NETHERLANDS

A B S T R A C T Daniel Dennett, in Darwin's Dangerous Idea, argues that natural selection is a universal acid that eats through other theories, because it can explain just about everything, even the structure of the mind. Emanuel (Manny) Schegloff (1987) in 'Between Micro and Macro: Context and Other Connections' opposes the importation of 'macro' (sociological/sociolinguistic) factors into the 'micro' (interaction analysis), suggesting that one might reverse the strategy instead. Like Darwin, he is coy about whether he just wants his own turf, but the idea opens up the possibility of interactional reductionism. I will argue against interactional reductionism on methodological grounds: Don't bite off more than you can chew! Instead I'll support the good old Durkheimian strategy of looking for intermediate variables between systems of different orders. I try and make the case with data from Rossel Island, Papua New Guinea.

K E Y W O R D S : conversation, joking relationships, kinship, micro and macro contexts, Papua New Guinea, reference, Rossel Island

\section{Universal acid}

My starting point is Daniel Dennett's (1995) book, Darwin's Dangerous Idea, in which he argues that the idea of natural selection - 'descent with modification' in Darwin's one-liner - is a universal acid that cannot be bottled up. It eats through other theories, because it can explain just about everything: it can be applied to brain maturation, consciousness, culture, and all the furniture of the mind. Whether Darwin foresaw all these extensions of the theory is moot, but he certainly knew it was dangerous - he was only too aware of the corrosive effect on religion, and so sat on the theory for 20 years (certainly Marx and Nietzsche saw the dangerous extensions immediately). Today, there are two schools of Darwinism, the 'soft Darwinists' (Gould, Lewontin, Rose) who think that natural selection can be contained, and must be supplemented by many other processes, 
and the 'ultra-Darwinists' (like Dennett and Dawkins) who embrace the dangerous interpretation of the idea and pursue its consequences wherever they take us.

It seems to me that there is an analogy with the 'soft' and 'ultra' theorists in the study of human verbal interaction. A number of enormously creative and insightful scholars - such as Birdwhistell, Bateson, Garfinkel and Goffman opened up that field, but few have done as much to establish the foundations of a new discipline as Emanuel (Manny) Schegloff. The contributions that he and his fellow conversation analysts have made to understanding the systematics of human social interaction have been unparalleled. For current purposes, let's take him as our Darwin. Now, Schegloff (1987), in the essay 'Between Micro and Macro: Context and Other Connections', opposes the importation of the macro (sociological/ sociolinguistic) into the micro (interaction analysis), suggesting innocently that one might reverse the strategy instead. What he specifically argues against is fishing expeditions by the macro-theorists, whereby they drop lines into the interaction waters hoping to catch fish they have already labelled 'power' or 'gender', or the like. The reversal he suggests is that instead of thinking of social institutions as organizing and creating the interaction that takes place within them, we should rather think of interaction patterns as engendering the very social institutions themselves. The example he works through is persuasive: he shows how various US presidents have tinkered with the structure of presidential press conferences, only to find that the new arrangement has a quite unintended life of its own.

The kernel idea - the dangerous idea of my title - is that social order is the local product of interaction. Stated thus, it seems innocuous enough. But suppose we read it as all social order, everything - from institutions to economics, from kinship to politics, from etiquette to grammar. Now it is no longer so innocent - in fact then we would have a reductionist programme in the social sciences as 'dangerous' as ultra-Darwinism in biology.

Like Darwin, Schegloff is actually coy about how far he wants to push the idea. ${ }^{1}$ There are two plausible interpretations. The 'safe' interpretation is a theory that holds that interaction should be studied in its own right, as a system with its own distinctive properties. Only once we understand the system does it make sense to take its own integral variables and ask how they connect to higher-order social structures and processes. Meanwhile, the macro-fishermen should please stay off the interactional waters, since they are not the experts there. The 'dangerous' interpretation holds that interaction is indeed the fount of all social order. After all, it is through interaction that children learn about social relations, institutions, grammar, and ways of thinking. All these higher-order levels depend for their existence on re-enactments at the interactional level - in the last analysis they are abstractions from the behavioural realities of the interactional level. The more you begin to think about it, the more dangerous the idea becomes.

Let's just rehearse the ideas a little further. The model that Schegloff is 
decisively rejecting is a view where cultural rules and social systems, on the one hand, and linguistic rules, on the other, are the locus of social order, and interaction is merely the football pitch, as it were, where these are deployed, as the traditional talk in terms of 'social roles being played out' or 'competence being deployed in performance' suggests. What's wrong with that view is that interaction has a life of its own as a system, and has the habit of kicking back, as in the organization of presidential press conferences. The 'safe' interpretation would treat each of these levels, say, the sociocultural system, the linguistic system and the interaction system, as separate but equal. We can acknowledge that the interaction system deserves a science of its own, and that those seeking connections to other levels had better understand the workings of the interactional level. But no system is accorded ontological priority. The 'dangerous' interpretation, on the other hand, places the interaction system centrally and threatens to reduce all other systems to outcomes of the workings of interaction. One can see this tendency in, for example, the language socialization literature (see e.g. Schieffelin and Ochs, 1986), where sociocultural patterns are seen as routinized interactions, or equally in the interactional linguistics literature, where grammar is thought of as frozen interaction (see e.g. Ochs et al., 1996; Ford et al., 2002). Pushing this programme through to the hilt would amount to interactional reductionism.

\section{Some working presumptions about the interplay between language, culture and interaction}

The invitation to contribute to this special issue has made me think a little bit about where I stand on these issues. In the work on 'politeness' (Brown and Levinson, 1987), our central idea was that a few key parameters of social relationships are the key to the 'micro-macro link': the nature of verbal interaction is tied to culture and social institutions through the way in which social relationships are conducted. In my work on pragmatics (Levinson, 1983, 2000), the science of the unsaid, I have been preoccupied with the key idea that rich principles of interpretation allow minimal verbal expression, thus linking grammar to usage in interaction. Finally, in my work on the relation of language to cognitive style (Levinson, 2003), the central idea is that language-based cultural specializations in thinking afford distinct interactional styles, thus linking language to interaction through mind ('cognitive style'). In none of this work have I been an interactional reductionist - I have treated interaction, grammar, and culture as systems in their own right. True, they make essential reference to one another, as when social institutions, grammar, and interaction come together in specialized activity types or speech events (Levinson, 1992), as in a law court where the system of social sanctions, the grammar of questions, and the special turn-taking interact to form a micro-system. My background working presumption has been that you don't get a better model by reductionism in any direction. Rather, by the methodological principles of 'divide and rule' and 
'don't bite off more than you can chew', complex behaviour is best understood as a system of interrelated systems. The models I have used, without too much ratiocination it has to be admitted, essentially involve independent systems (linguistic, sociocultural, and interactional) linked together in the Durkheimian manner, that is, by focusing on crucial intermediate variables. Thus, types of social relationship link linguistic systems to social systems, inferential heuristics link cultural systems to linguistic systems, while cognitive styles link interaction systems, cultural systems and linguistic systems. The piggy in the middle, the area from which these Durkheimian intermediate variables are plucked, is Mind - it is mental parameters (such as cognitive styles), mental templates (such as social relationships), and mental habits (such as inferential heuristics) that hook the three major systems together.

But having confessed to my presuppositions, I should also confess to having held these views without sufficient self-examination. And when I consider the 'dangerous' interpretation of the role of social interaction in human life, I do not find it easy to shrug off (in fact, Schegloff's paper has always unsettled me ever since it appeared). So in this article I've set myself the task of seeing whether I can retrospectively muster support for the 'safe' interpretation. Let's see if it can be done.

\section{Rossel Island, Papua New Guinea - the ramifications of kinship}

I choose the ground on which to argue carefully. I will draw on details from an ethnographic setting, because these alien settings have a way of refreshing our vision. The society in question is located on Rossel Island, the last island off the eastern tip of Papua New Guinea. ${ }^{2}$ The island lies just outside the boundaries of the Kula ring, due both to geographical isolation and to the fact that the language and culture are not akin to those of the surrounding Massim peoples the 4000 inhabitants speak a 'Papuan' language, actually an ancient isolate, called Yélî Dnye. In the days when students still read ethnographies, the Rossels were famed for their intricate system of shell money (Armstrong, 1928). I will deal mainly with two of our levels, the sociocultural level and the interactional level, focusing in the case of the former on the kinship system and in the case of the latter on systems for person reference.

The kinship system of Rossel Island is dominated by matriclans and matrilineages - descent groups traced through the female line. These regulate much of social life, including especially marriage, which is exogamous of the clan (there are 15 effective clans), the payment and inheritance of valuables, and the distribution of sorcery accusations. The importance of kinship can be gauged from the fact that adults have in their heads genealogies 10 generations deep covering a thousand individuals. The details of the kinship system, which also has a strand of patrilineal reckoning, would take us far afield (see Levinson, in preparation). 


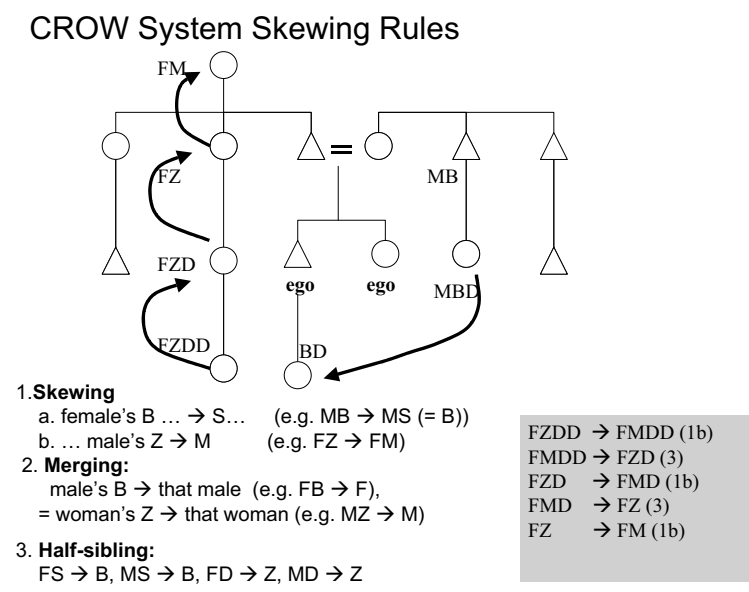

FIGURE 1. Some special features of matrilineal kinterm systems

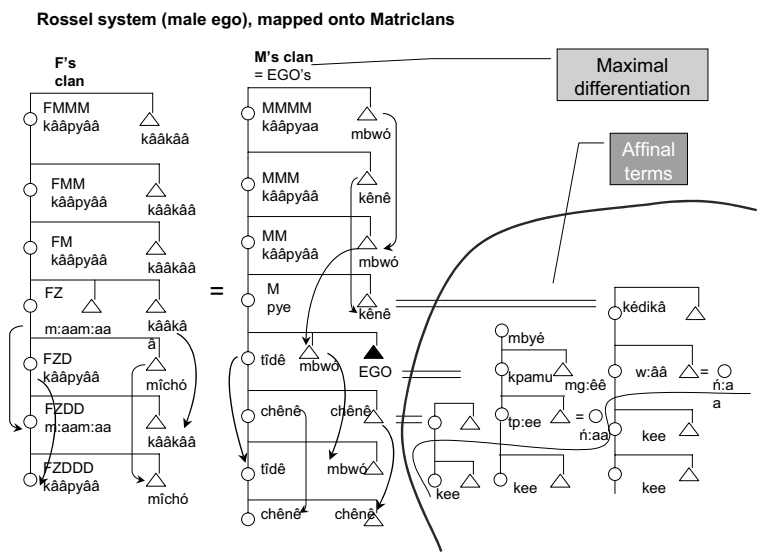

FIGURE 2. Terms which alternate across generations, and affinal terms

If kinship is, par excellence, a sociostructural matter, it nevertheless has direct repercussions on another of our levels, the linguistic system. There is a serious linguistics of kinship. The first element is the system of kinterms. The kinterms belong to a type known in the trade as a Crow III system (Lounsbury, 1969), with a specific kind of cross-generational skewing, whereby, for example, a father's sister (FZ) one generation up from ego counts the same as a father's sister's daughter's daughter (FZDD), one generation down from ego. These generational collapses can be expressed by 'skewing rules' as in Figure 1. On top of these rules is mapped a rule of alternating generations, so FZ is called differently from FZD but the same as FZDD, as in Figure 2. Again, the full details don't concern us here. But it is well known that such skewed kinterms correlate almost without exception with matrilineal descent systems. Another interesting property of the 


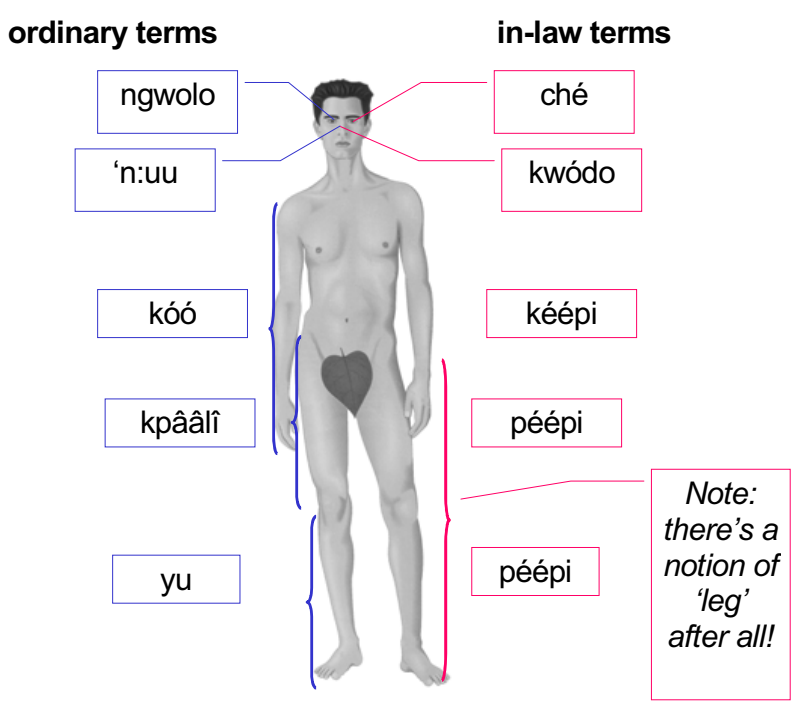

FIGURE 3. Comparison of some words for body parts in ordinary language and in-law language

kinterm system is that it has terms for kin dyads: thus, there is an unanalysable term chimi meaning 'a man with his sister's son', or ghee meaning 'woman with her offspring or sister's offspring', where the matrilineal theme is also clear.

I am under no illusions that many readers of this journal will be very interested in these anthropological details. But the general point is important: a feature of the social structure - namely matrilineal reckoning of kin - is reflected directly in a linguistic subsystem. But there are also other repercussions of a matrilineal system of kinship on the linguistic system. One of the more interesting of these is a taboo vocabulary used exclusively to affines - those connected by marriage rather than descent. (The scope of the affinal kinterms is shown in Figure 2, in which one notes that in a matrilineal kinship system a man's offspring belongs not to his descent line but to that of his wife, they are kin only through an affinal link.) In the presence of one's spouse's parents or siblings, ordinary words for clothing, intimate possessions and body parts may not be used. Instead, an alternate set of terms is used, as illustrated for body-part terms in Figure 3, where one can see there are alternate words for eye, nose, arm, etc. The kind of detail here that excites anthropological linguists is that in the ordinary language there is no word for 'leg' - instead one must use different words for upper leg and lower leg: but in the taboo language, there is only a more general word which covers both parts with a single term for 'leg' (see Dixon, 1971, for the generalizations here), showing that Rossel anatomical ontology is not so strange after all.

But again, the relevant point here is that the matrilineal kinship system imposes itself on the language, in what could be called 'bystander honorifics' (see 
Levinson, 1983: 90-1), that is to say terms that indicate that respect is being given not to persons spoken to, but to those who just happen to be within hearing. But now we are moving into our third level or system: the interaction system. The language use here is just part of a larger set of interactional constraints between in-laws. Affines cannot share 'free goods' - the tobacco and betel nut, utensils, and so on that normally can be freely borrowed or begged. Nor can they get close to or touch affines, or their belongings or clothing. And they certainly cannot address them directly, or look them straight in the eye. In interactional terms, in-laws have restricted rights of participancy - they are part of the respected furniture, not part of the action, and one talks indirectly in their presence in the same way one whispers in church.

\section{A mysterious genre of joke}

There's much that happens on Rossel Island that I still fail to understand. One of these mysteries I did finally unravel. People sometimes burst into laughter at some invisible joke. Now humor, like wine, is well known not to travel well, but still some of these cases seemed peculiarly obscure. Consider the following. Waiting for the church congregation to get its act together, sit two individuals I'll call A and B, with some boys behind them. A schoolteacher has been yelling inanities through a megaphone, and suddenly B says:

(1) r03_v20_s5 00:00:32-

1 B: $\quad$ taa ghi u mênê wunê mbumu

'He's yelling into a bit of bush-knife'

(0.9)

2 boys: (giggles)

(0.5)

3 B: $\quad$ taa ghi u mênê wunê mbumu

'He's yelling into a bit of bush-knife'

4 A:

kêle

5 boys: (2.8 secs of giggles)

'No' (looks away)

6 A: ghêêî puu km:ee wunê mbumu

'He's yelling under a mangrove tree'

$\begin{array}{llll}7 & \text { B: } & \text { kêle } & \text { nîmo taa ghi u mênê wunê mbumu } \\ & \text { 'No } & \text { we are going to talk into a bit of bush-knife' }\end{array}$

[ [

B's joke - judging from the giggles of the boys in line 2 - is met by A with a chagrined grin. B repeats the joke and when the giggles die down, A ripostes in line 6 , with both A and B now smiling, and everyone has a giggle. Some of the flavour can be got from the sequence of stills taken from the video in Figure $4 .^{3}$ 

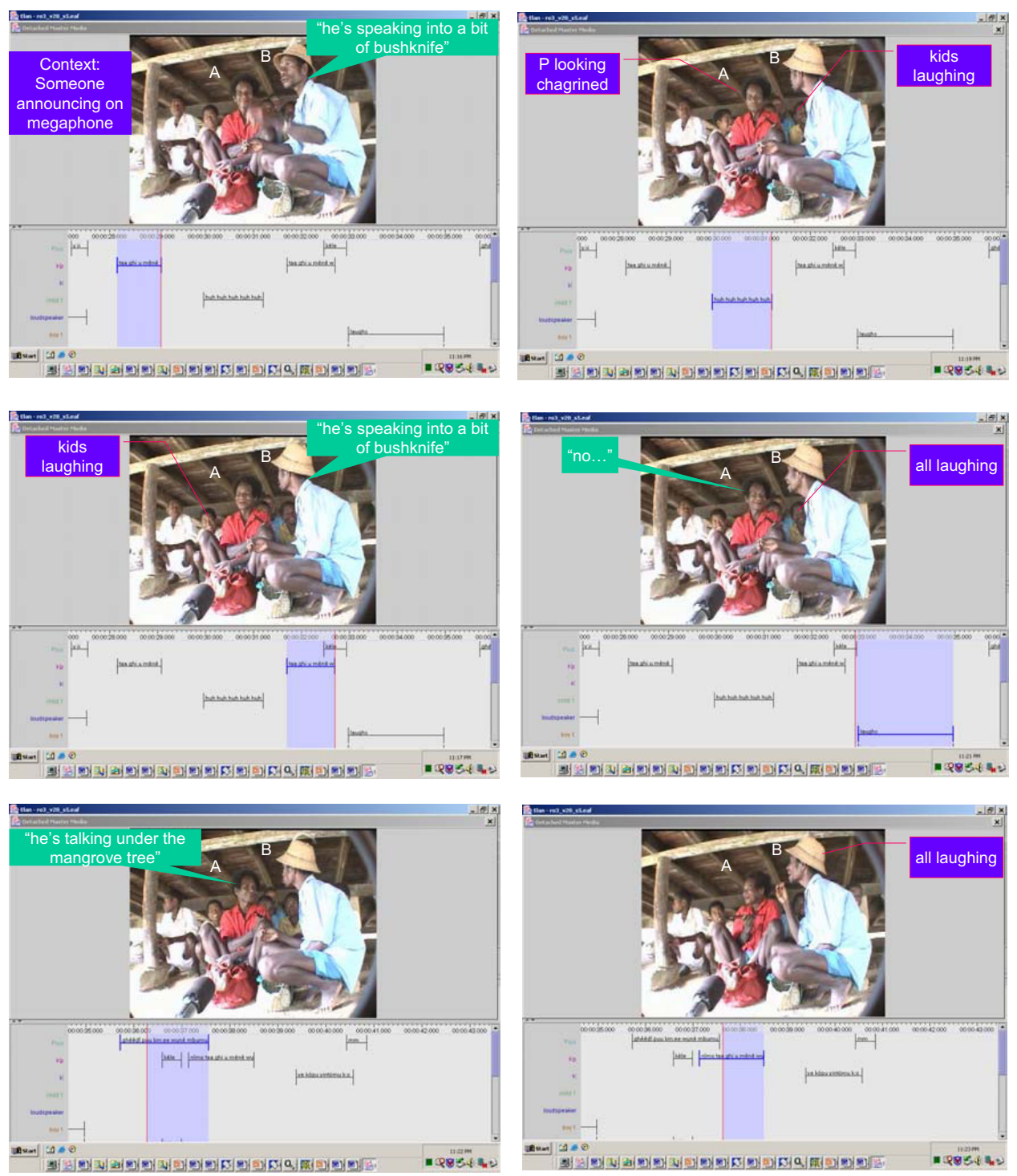

FIGURE 4. The father-in-law joking sequence in example (1) (read left to right, then down)

The puzzle for me was why is talking into a bush-knife either relevant or funny, and what's this about being under a mangrove, given that we are far from the beach where such trees can be found? A further puzzle is that although this laughter has the feel of 'universal laughter', Rossels don't receive a good joke with normal ('universal') laughter - jokes are properly received with a culturespecific sequence of three carefully synchronized whoops simultaneously with a shaking of hands. The sequence of stills in Figure 5, taken from another interaction, gives some idea of what this looks like. 

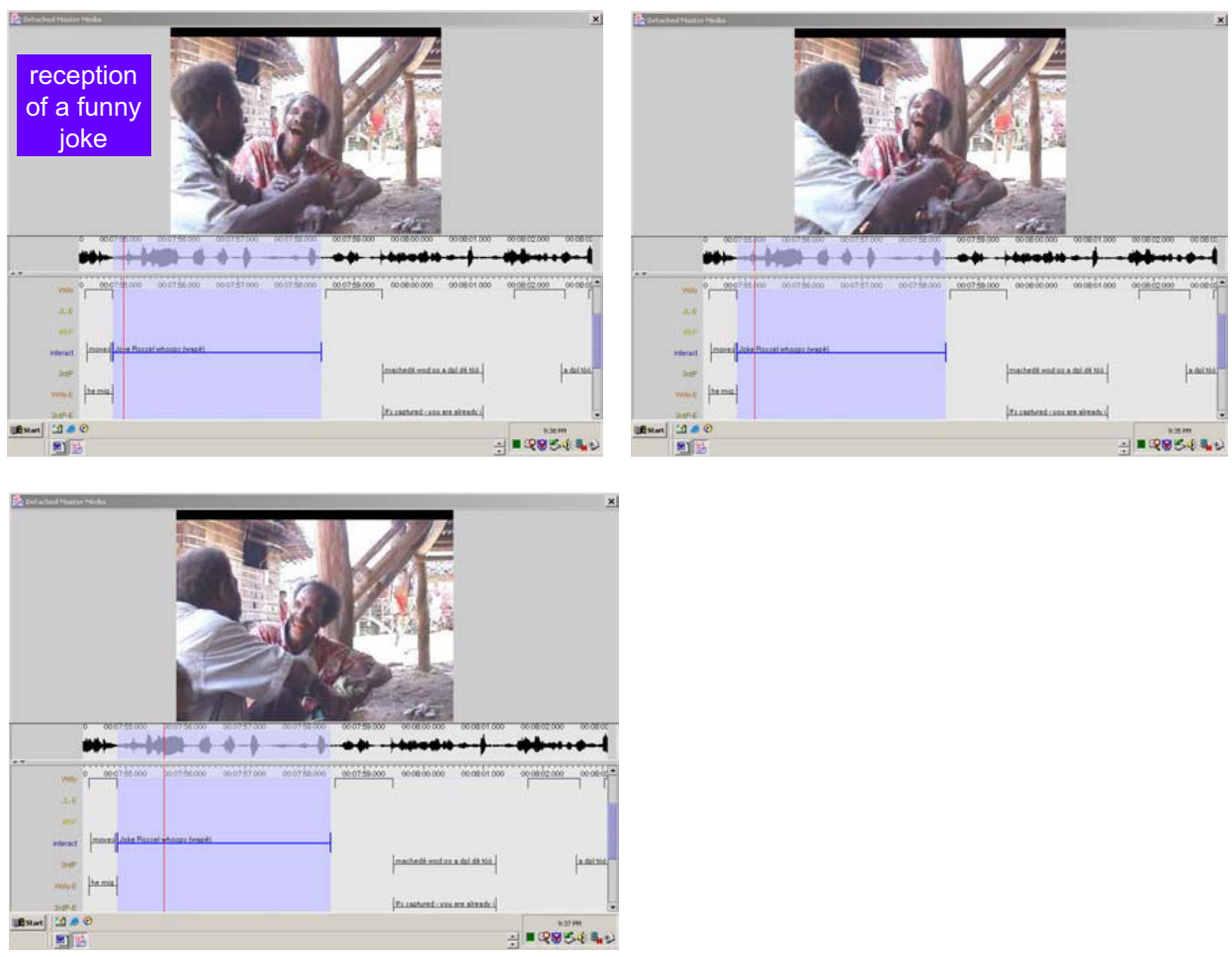

FIGURE 5. Mode of receipt of a 'real' joke

So it turns out that the jokes in example (1) are not 'funny-funny jokes' - the giggles are the way in which ribbing, i.e. jokes at another's expense, are properly received. But what's the joke? The locals decoded it for me. When B says, 'He's speaking into a bit of bush-knife' this is an oblique allusion to A's father-in-law, who killed his wife with a bush-knife before committing suicide. And when A responds, 'No, he's talking under a mangrove tree', this is a parallel allusion to B's father-in-law, who fell down from a mangrove tree and died horribly from his injuries. From this I learned that there is a whole genre of father-in-law jokes, and from then on people would nudge me to make sure I got them: they nearly always involve some grisly, miserable happening to the poor father-in-law, or at least some mockery of his apparel or habits.

So why would some peoples have mother-in-law jokes, and some peoples have father-in-law jokes? You can find the answer in classical kinship theory. For example, Lévi-Strauss (1958) argued that instead of thinking of the nuclear family (mother, father, children) as the 'atom' of kinship, the real 'kinship atom' is composed of mother, father, children and mother's brother. Following Radcliffe-Brown (1952), he noted that whereas in a patrilineal society, dad is the authority figure, and the uncle (mother's brother) the affectionate friend, in a matrilineal society the mother's brother is the authority figure, and dad the 


\section{Lévi-Strauss's 'Kinship atom'}
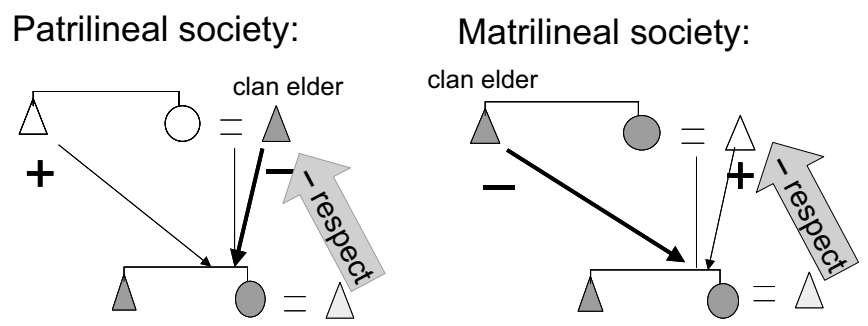

\section{Joking marks ambivalent (+/-) kinship relations}

FIGURE 6. Distribution of attitudes across the relations of the 'kinship atom' in patrilineal and matrilineal systems (ego is bottom left triangle)

friend. That's because in a patrilineal system authority and assets flow through the father's line, whereas in a matrilineal system, the power and assets flow through the mother's line, represented by the mother's brother. Figure 6 should help to make clear the different distribution of affection (marked +) and authority (marked - ) in these two systems. ${ }^{4}$

A young man (bottom right triangle) marrying the daughter in this atomic configuration naturally owes respect to the bride's father and her mother's brother - they are affines, and on Rossel we have already seen how they are treated with avoidance-respect, using the taboo language reserved for in-laws. Still, there's a difference in the relation of groom to father-in-law in the two systems. In the patrilineal system the father-in-law is the bride's authority figure (her dad) - she owes him respect, just as her new husband does: there's a match of attitudes. But in the matrilineal system, the groom's father-in-law is the bride's affectionate friend (her mother's brother is the authority figure, not her dad), while the groom owes him elaborate respect: in short, there is a clash of attitudes (again, see Figure 6 for clarification). Now when there is a mismatch of projected attitudes, kinship theorists predict 'joking relations': if A owes B both respect and friendship, then A and B may overtly joke with one another. In the Rossel fatherin-law case at hand, though, we have a triangle, where A (the son-in-law) owes $\mathrm{B}$ (the father-in-law) respect, but A is married to $\mathrm{C}$ (a relation of intimate equality), and $\mathrm{C}$ has a friendship relation to $\mathrm{B}$ (her dad) - there is a triangular mismatch, not a direct one. This is what generates the tension that makes it possible for some other individual to joke to A about B, a joke A could never make, but which he can still find sort-of-funny.

So there's a calculus of kinship, which gives us a calculus of attitudes, which predicts for any type of kinship system where the joking tensions will be. We can 


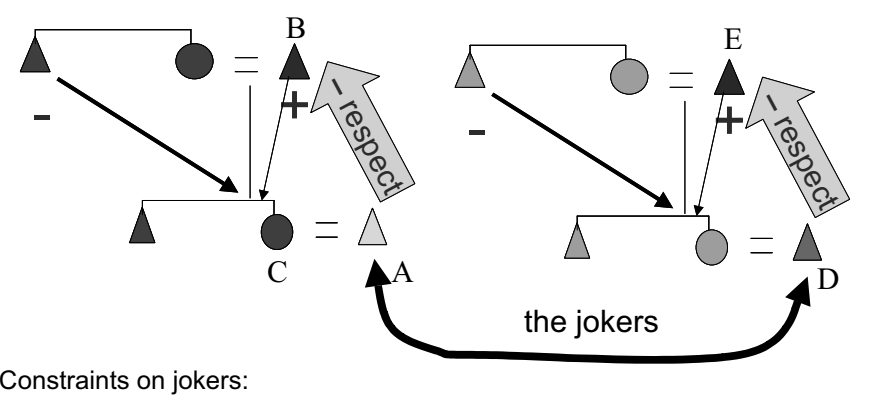

1. $D$ can't joke to $A$ about $B$ if

(a) D and B are in the same clan - then D would be insulting his own uncle!

(b) A is in same clan as $E$ - since then A could not reciprocate the joke

2. Jokers must be coeval males

FIGURE 7. The relationships implied by Rossel father-in-law jokes

take the reasoning a bit further: in the Rossel case, not just any person $\mathrm{D}$ in any kinship relation to A can joke with A about his father-in-law. If D was in B's matriclan (i.e. the same clan as the father-in-law), such a joke would be an "own goal'. Since the joke will be reciprocated, $\mathrm{D}$ has also to ensure that his own fatherin-law (to be butt of the next joke) is not e.g. in the same clan as A (then D would be putting A in a position where he must insult himself). Finally, A and D have to be males of the same generation, otherwise the reasoning doesn't work. See Figure 7 for diagrammatic help with these restrictions between the jokers.

I come now to the point of all this. Comparative kinship theory (on which, see e.g. Meyer Fortes, 1969), ranging over matrilineal, patrilineal and cognatic systems, predicts the character of kinship joking, and more crucially, it tells us in which social relationships in any society it is likely to occur. Comparative kinship theory is, of course, not in the heads of our jokers - they take the local kinship ecology for granted, and will joke only in the right ecological niche. But if we want to know exactly why this joke occurs here in this conversation right now, and how it is recognized and received, well, now we need a different level of analysis, a theory of interactional systematics (see e.g. Sacks, 1972). I present this as an example of why we need TWO distinct levels of analysis, comparative sociocultural theory and interactional theory, not just one. They each tell us different things, and they are in different people's heads - knowledge of comparative kinship theory is restricted to the bird's-eye view of the social theorist, while the principles of interactional systematics must be in the heads of the interactants, otherwise they will make a mess of it. 


\section{Culture and naming: the interplay between cultural systems and interactional systematics}

Let's now focus more on the level of interactional systematics, while still continuing our kinship theme. We have seen that in the presence of affines, the use of the taboo in-law language is required. But the taboos extend wider. All sorts of relatives, including the recently dead and living affines, should not be mentioned by name. How are these naming taboos actually handled in interaction? Let's look at a case:

(2) Managing a daughter-in-law naming taboo (R03_v6 00:00:8:09)

1 N: wu dmââdî a kêdê Thursday ngê anê lóó

'That girl told me she would go across on Thursday'

2 P: n:uu ngêe?

'Who did?'

$3 \mathrm{~N}:{ }^{\circ}(\text { yi dmâ̂âî })^{\circ}$

'That girl'

4 P: Mby:aa tp:oo módó ngêe=

'The daughter of Mby:aa did?'

$5 \quad$ M: =Kpâputa u kpâm?

'Kpâputa's wife?'

$6 \quad$ P: Kpâputa u kpâm?

'Kpâputa's wife?'

[

7 M: ee! ee! kî tpóknî mwi lee dmyino, Stephen a kwo, mwi lee dmyino ó!

'Hey kids go over there, Stephen is here, go right over there!'

$8 \quad \mathrm{~N}:$

EBF

Head-point East

9 P: Kpâputa u kuknwe apii?

'Kpâputa's widow, right?'

10

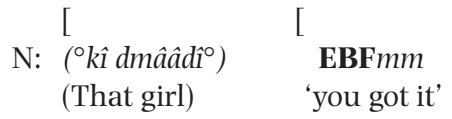

11 M: (to kids) ka, tin ghi mwi 'nuw:e, mwi pââ y:i,

'OK take the tins over there, run off over there'

(conversation lapses)

The reference in line 1 to 'that girl' (with the deictic wu indicating 'invisible, only indirectly ascertainable') is used by $\mathrm{N}$ to introduce a new sequence. The reference is vague to say the least, and P doesn't get it: he asks 'Who?' But what we then get is not a name, but a sotto voce repetition of 'that girl' (now with a different deictic yi, 'that as previously mentioned'). $\mathrm{P}$ now guesses who it could be, $\mathrm{M}$ offers another guess which $\mathrm{P}$ pursues, eventually obtaining from $\mathrm{N}$ an eyebrow 

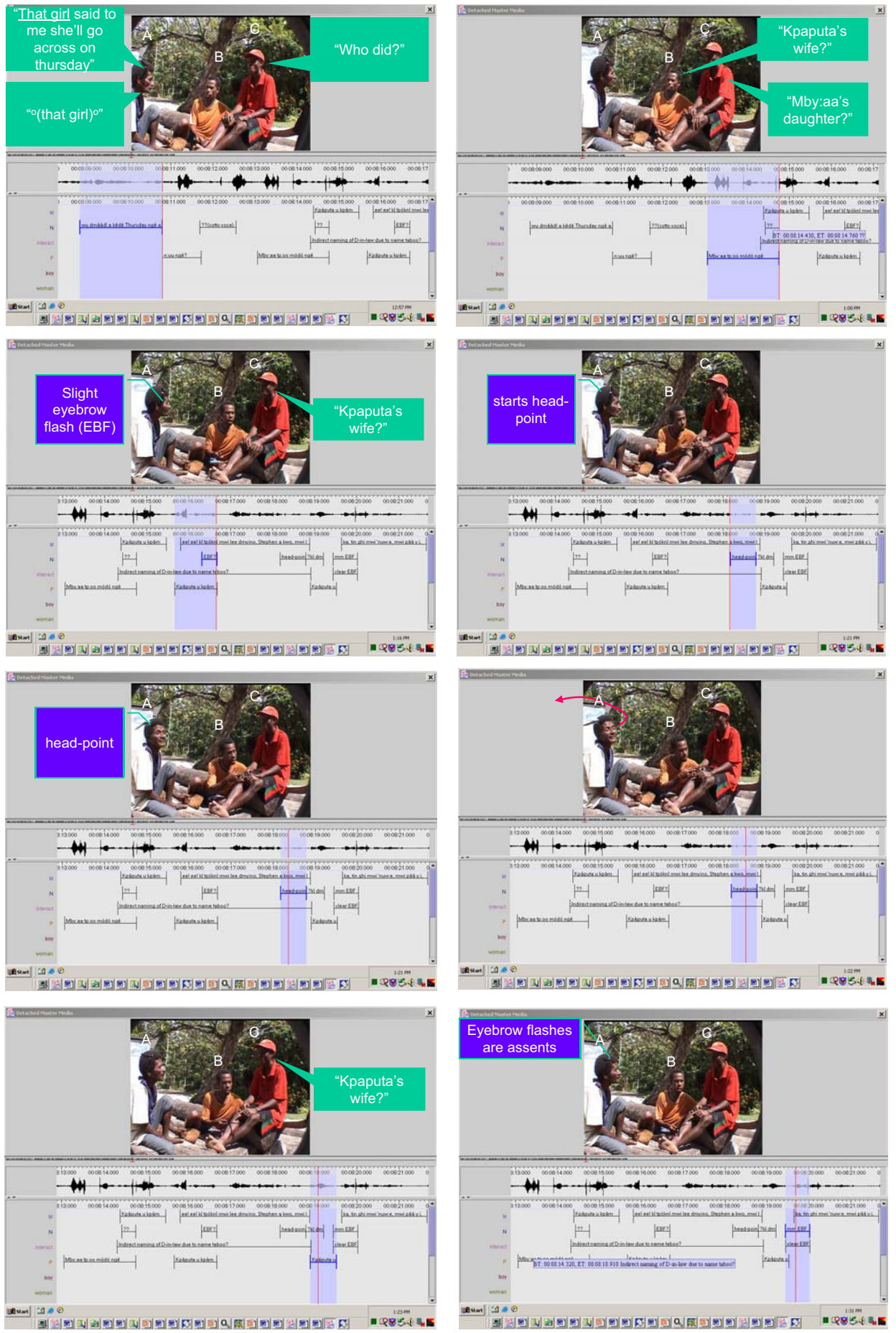

FIGURE 8. Frame sequence corresponding to example (2) 
flash (marked EBF in the transcript), which signals either 'yes' or 'go on', followed by a head-point to the East (this in overlap with $\mathrm{M}$ talking to kids in line 7). A reformulation of the guess in line 9 (from Kpâputa's wife to Kpâputa's widow) gets a clear eyebrow flash and 'mm' in line 10. Figure 8 provides a sequence of stills which give a better idea of how the sequence runs off.

The problem here is that $\mathrm{N}$ is talking about his daughter-in-law, an affine he should not name, moreover one once married to his dead son. Reference is achieved by first using a general description, 'that girl', then letting his interlocutors generate descriptive guesses, to which he can assent in a minimal form (sotto voce, raised eyebrows). He provides one additional clue, namely the head-point to the home-base of the girl in line 8. Notice that his interlocutors have quickly realized the nature of the problem, namely that $\mathrm{N}$ wants to mention someone he can't name, for in their guesses (lines 4, 5, 6, 9) they avoid offering the name of the girl, choosing naming instead a relative of hers, and specifying her relation to that relative.

Now anthropologists might be tempted to say at this point: 'You see! There we have it, another cultural idiosyncrasy, showing us once again how hopeless the idea of a universally applicable conversational systematics would be.' But if we dig a little further, we will see that this Rossel practice is not so divorced from the practices familiar in English. To see this we need to revert to Sacks and Schegloff's (1979) dense little note on person reference (see also Schegloff, 1995). They note that there seem to be two preferences which govern the choice of referring expressions for persons. The first is a preference for achieving recognition, that is, using a name or a description (a recognitional) which allows recipients to realize that they know the person referred to. The second is a preference for using a minimal form to do the job, for example, a first name alone. Clearly, these can often both be satisfied simultaneously, as when I refer to one of the editors of this special issue as 'Sandro' and that's precisely the name by which you know him. But sometimes a minimal form may not be sufficient - and in that case, speakers will often try a minimal form with a rising intonation (a 'try marker'), and if recognition is not forthcoming, will then incrementally augment the expression with e.g. another name:

(3) Sacks and Schegloff (1979: 20)

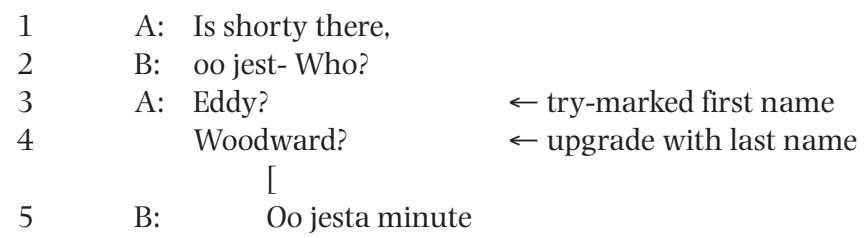

Sacks and Schegloff take this kind of sequence as evidence for a ranking between the two preferences: Go for recognition if you possibly can, and successively relax minimization until recognition is achieved. 
If we now look back at the Rossel sequence, here repeated in English gloss minus the interruptions, we see that the sequence has a passing similarity to the English Who?-engendered sequence:

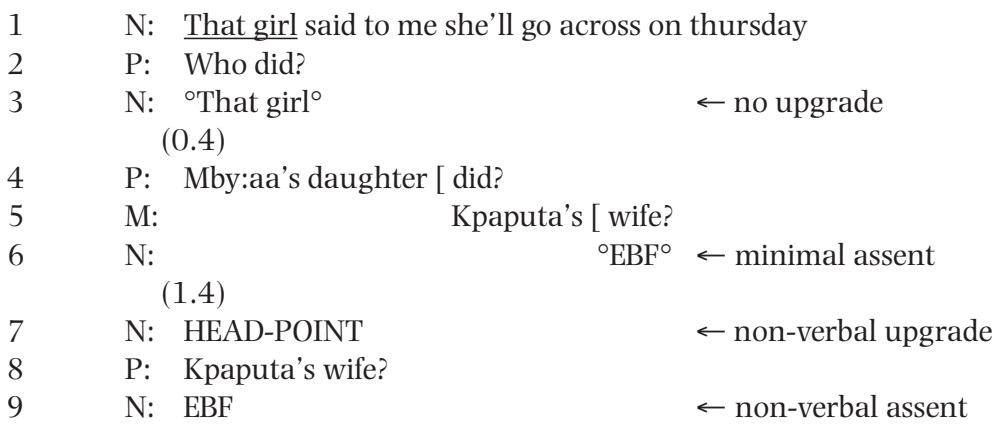

Both sequences are triggered by 'Who?', thus indicating that recognition is being pursued, both in response to a minimal referring expression. Although in the Rossel case no verbal upgrade later follows, a non-verbal upgrade does eventually appear at line 7. Clearly, there's a serious impediment in the Rossel case, for the reasons we now understand - it is as if $\mathrm{N}$ has temporary culturally imposed aphasia, and $\mathrm{P}$ and $\mathrm{M}$ must do the guessing typical under such circumstances (see Goodwin, 2003). But nevertheless there's evidence that the same two preferences are in play, and with the same ranking, and a successive relaxation of minimization is employed until recognition is achieved.

A nice payoff from seeing the commonality between the English and Rossel sequence is that we appreciate that this procedure for reconciling two preferences in conflict, namely the successive relaxation of minimization, gives us a local, possibly cultural, metric for what counts as minimal. By this metric, Rossel pointings and eyebrow flashes count as more minimal than their verbal equivalents. $\mathrm{N}$ has never said the taboo word, nor has he even given further verbal clues to it - recognition has been achieved by a gesture and non-verbal assents to guesses. This, in fact, has cross-cultural application: it's a commonplace of the ethnographic literature that the gestural takes over from the verbal in situations of taboo - consider Trappist signs, or the Warlpiri sign-language used by widows (Kendon, 1988). Incidentally, pointing in Rossel interaction has a much more fundamental role than in Western societies, because Rossels have an 'absolute' system of spatial orientation which allows them to point accurately to distant places knowing that their interlocutors can interpret the point precisely without supplementary language (see Levinson, 2003, on 'absolute' spatial systems). Consequently, even when a name is given, there is often an accompanying point to the person's home base - in these taboo situations the name has gone, but the point remains. 
To see that the partial match between the English and Rossel examples is not an accident, compare the other kind of sequence that Sacks and Schegloff (1979) draw attention to. In the first type, just reviewed, the recipient has a problem with a reference, and instigates the sequence with 'Who?' In the second type of sequence, the speaker foresees that the recipient just may have a problem with a reference, and so try-marks it on first usage. Once again, the first try is minimal, and when that doesn't succeed, the reference is upgraded, perhaps by a second name, and if that doesn't work, by a description. Consider:

(5) Sacks and Schegloff (1979: 19)

1 A: ... well I was the only one other than the uhm tch Fords?, $\leftarrow$ try-marked name

2 Uh Mrs Holmes Ford?

$\leftarrow$ try-marked upgrade

3 You know uh the the cellist?

$\leftarrow$ try-marked upgrade

4 B: Oh yes. She's she's the cellist

5 A: Yes well she and .......

So again, the sequence type indicates preference for recognition being more important than minimization, while the successive, step-by-step relaxation of minimization indicates that it is only reluctantly departed from.

Now compare this to the following Rossel sequence:

(6) R02 v4 s1 Demo_Person 2 3:29

1 J: mu kópu mwo a pyaa wo, mu $\underline{\text { dmââdî }} \leftarrow$ try-marked on underlined 'The thing that happened a while ago?, to that girl?' [points $S$ over mountain to her natal village]

2 (.)

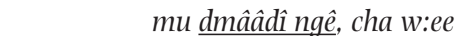
'That girl?, you see?' [points $W$ to where she died] $\leftarrow$ try-marked on underlined

4 J: yi dmââdî pi kuu, yed:oo nipi nmî dmââdî cha w:ee, 'That girl is not separate from us, she's our girl'

Now in this sequence, yet again, the speaker is tongue-tied. He wants to refer to a girl who comes from his village, but she has just died (the reason he is raising the topic is that he should really be at her mortuary feast right now). By the name-tabooing rules, he should not name her. So in line 1 , he mentions 'that thing', the unfortunate death, pointing over the mountain to where the girl came from, with a try marker (sharp rise-fall) on 'that thing' and 'that girl'. He looks at the recipient $\mathrm{R}$ throughout, holding the gesture, but $\mathrm{R}$ shows no sign of recognition. When there is no uptake in the slight pause, J repeats the same indeterminate phrase 'that girl', opening his eyes wide as another 'try-marking' signal, but now supplementing the description with another, different gesture, indicating in fact where she died. (As mentioned, gestures to a person's home-base, 

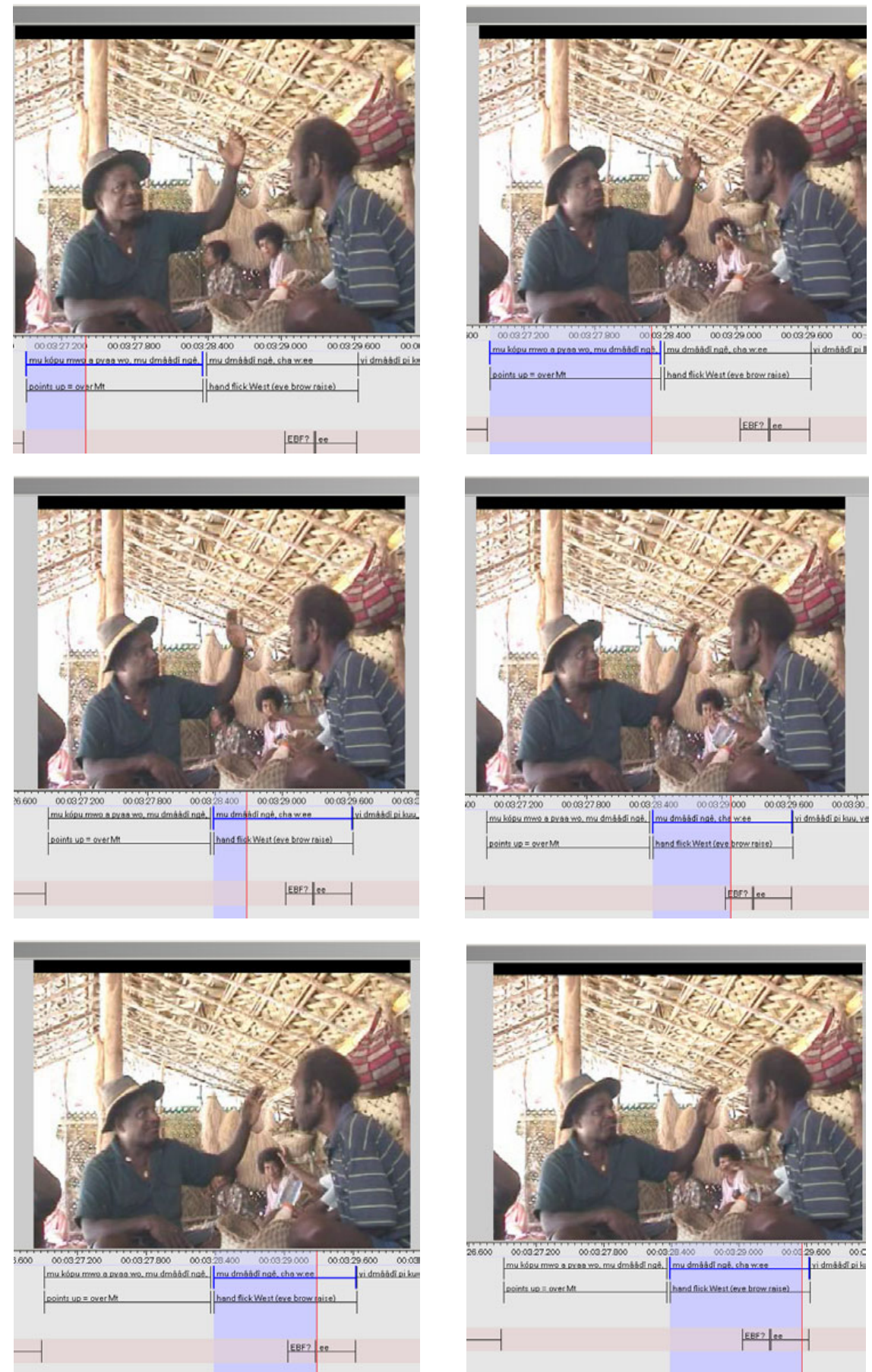

FIGURE 9. Frame sequence corresponding to example (6) 
as in example (1), are quite standard, especially in these name-taboo cases, so the gesture accompanying the second try in line 2 can be taken as giving a substantial second clue to the girl's identity. The first gesture is a point, the second gesture with a flat palm suggests 'lying down', as in dead!) Recognition is now achieved, signalled by an eyebrow flash in overlap with the tag in line 2 , and a 'right'. As soon as it is achieved, J proceeds, just as in the English example. See Figure 9 for a sequence of stills.

To summarize: Rossel people have an 'exotic' naming taboo for in-laws and the recently dead. Yet when we look at how this taboo is handled in conversation, we see that, nevertheless, sequences where person reference is in doubt look closely analogous to English ones. Let's see if we can formulate the similarities and differences. One way we can think about it is that Rossel simply has an additional preference folded in to the two English preferences. For English, all we need is something like this:

(7) English preference rules for person reference (after Sacks and Schegloff, 1979)

Preference 1: Use a recognitional form if possible

Preference 2: Use a single or minimal form if possible

Resolution: When 1 and 2 are in conflict, apply 1 and relax 2 successively until recognition is achieved

For Rossel we need to fold in the additional preference rule about not naming taboo persons:

(8) Rossel preference rules for person reference

Preference 1:

a. Use a recognitional form if possible

b. If not possible by Preference 3, go for recognition elsewise (e.g. by pointing)

Preference 2: Use a single or minimal form if possible

Preference 3: Don't use a recognitional form when referring to a taboo relative

Resolution:

(a) When 1 and 2 are in conflict, apply 1a and relax 2 successively until recognition is achieved (as in English)

(b) When 1 and 3 are in conflict, apply $1 \mathrm{~b}$, and relax 2 successively until recognition is achieved (e.g. by gesture or indirect reference)

The English rules are not then superseded, they are rather supplemented. And this is just as well, since investigation of other languages seems to show something like the English rules clearly at work too (see Levinson, 2004, for a little evidence). In fact, I take it as a reasonable presumption that they form a universal base in this domain. In that case, what this rendition makes clear is that the Rossel case folds the universal and the culturally specific into a unified procedure. And this gives us an interesting model for thinking about this important domain of person reference, which is a domain where cultural factors, if anywhere, ought to be much in evidence. 


\section{Models for the interaction of language, culture and interaction}

Let's come back to the central issues by way of a summary. I have followed two rather different lines of reasoning about culture, language and interaction on Rossel Island. In the first, we followed the road of kinship theory. We looked at the Rossel kinship system with its dominant theme of matriclans. We saw how this impinges on the language, with its Crow-type kinterm system, and its in-law taboo vocabulary. We also saw how it impinges on the interaction system, importing rules of avoidance behaviour, and constructing a special kind of joking: father-in-law jokes, with their distinctive mode of reception. Finally, we saw how the name-taboo on in-laws and the recently dead kin affects the microsystematics of person reference in conversation. Now we bought many of these insights courtesy of comparative kinship theory. Such a theory is a macro-level, 'bird's-eye' theory which is by essence comparative across societies. Such a theory is not available to the participants in interaction - it is not a theory for interaction, although it is a theory much concerned with predicting properties of interaction, like joking behaviour, in-law avoidance and name-taboos.

What this suggests, to me at least, is that it is essential to keep our levels separated. Higher-order generalizations about sociocultural systems can have explanatory power for understanding interaction systems, just as they help us understand aspects of language like kinterms, taboo vocabulary or honorifics. The model suggested is of three distinct levels of analysis, or three different kinds of systems - sociocultural systems, interaction systems and language systems interlocked in various ways. One doesn't have to be a realist about these entities - one can treat them as analytical fictions, whereby one gets a better model of the whole shebang by finding relatively differentiated subsystems which seem to have organizing principles of their own.

But how then should one think about the interplay between these systems? I still think the old Durkheimian trick of finding crucial intermediate variables has much to recommend it: having analytically pulled things apart, we now need to find a way to zip them up together again. Thinking about kinship, for example, makes one realize that social relationships play such a role as crucial intermediate variables. The kinship system gives one $n$ types of social relationship. Each of these types carries interactional expectations and constraints (such as avoidance and joking in classical kinship theory), and each has linguistic reflexes in terminology and linguistic etiquette.

The second road we followed started to take interactional systematics seriously as a complex world of its own, concentrating on person reference. The principle of going for maximal effect (recognition) while maintaining minimal expression only works because there's a machinery that allows the minimal expression to be upgraded sequentially if necessary. This engenders the recognizable sequences we could find in both English and Rossel. And the culturally specific Rossel business of suppressing reference by name in certain cases can be handled within this machinery, mutatis mutandis. This suggests one model for 
thinking about how (putative) universal properties of human interaction may interact with culture-specific rules. That in turn would constitute steps towards a real science of human interaction.

Now a science of interaction could contribute much to a science of social systems. For example, as we have seen, it would allow us to cash out LéviStrauss's plusses and minuses, relationships of respect and familiarity, as procedures for 'being indirect' or 'being friendly' or 'being jokey'. Indeed, the whole business of the texture of social relationships belongs to a science of interaction. Taboo and avoidance relations are an interesting case in point: they may be expressed in a special linguistic system (as in the Rossel in-law vocabulary), and in other culturally specific mores (as in Warlpiri sign language), but the conceptual underpinnings belong to the theory of participation structure (Goffman, 1979; Goodwin, 1981): persons who stand in such relations are ratified overhearers, not possible participants. And the principles governing expression of such relations are interactional principles: we've also seen how taboos, for example, rely on a scale of minimality which itself can be precisely calibrated using the procedures for person reference.

In the same way, a science of interaction can contribute to a science of language in many different ways. Consider, for example, that we take the universal existence of short personal names for granted. In principle, things could be otherwise. Sacks and Schegloff's preferences suggest both plausible linguistic universals and the rationale for them: all societies have kinterms and proper names as established ways of meeting the two preferences for person reference simultaneously. Second, the principles of person reference are arguably just instantiations of much more general principles governing verbal interaction - connected closely I have argued to Gricean principles of inference (see Levinson, 1987). Those general principles, which really belong to the interactional level, can be seen to have a deep impact on language structure (see Levinson, 2000).

\section{Conclusion}

I have argued for the 'safe' interpretation of Schegloff's principle that social order is the local product of interaction. The 'safe' interpretation holds that, yes, interaction is properly seen as constituting a system in its own right, and, yes, we should not think in terms of interaction as playing out structures determined at another level. And we can understand the irritation of the interactional experts watching amateurs from other disciplines making a mess of interaction analysis: please stay off our turf, they are saying, until you understand the principles that govern this level. The 'safe' interpretation, then, is entirely consistent with the background assumptions I have worked with, as sketched in section 2, namely the idea of analytically separate systems, hooked up again through the study of crucial intermediate variables. 
So why does the 'dangerous' interpretation seem so attractive? Because there is a seemingly irrefutable logic that runs as follows: if there was no interaction, there would be no social system and no language. Moreover, for there to be this particular system, and this particular language, the society and language have to reproduce - children have to be inducted into it. And the only way this can happen is through interaction. Furthermore, what this social system (or this language) is turns out to be ultimately malleable - changes in the conduct of social (and verbal) interaction will engender changes in the fabric of institutions (and in the rules of language). That was the point of Schegloff's (1987) analysis of presidential press conferences.

But I think one can concede all that without buying the 'dangerous' interpretation, namely the idea that interaction determines every other level of phenomena, including social systems and linguistic systems. To see this, it's necessary to appreciate an important distinction between interactional reductionism and interactional constructivism. Interactional reductionism banishes talk of social systems or grammatical systems, in favour of a reconstruction in terms of interactional principles. But interactional reductionism has all the problems that radical reductionism has in any field - it throws out other levels of analysis at which principle and order can be better captured. ${ }^{5}$ Ultra-Darwinism in biology, i.e. Dennett's dangerous version of Darwin's idea, which reduces everything to genes, bypasses the organism and ignores the fact that natural selection works on phenotypes at the organism level, not directly on genes. In a similar way, interactional reductionism would throw out all the carefully nourished babies of comparative sociology, anthropology and linguistics with the bathwater.

Interactional constructivism, on the other hand, is not a pernicious doctrine at all. It holds that interaction constructs social relations, which in turn construct social institutions (the innocent reading of Schegloff's analysis of presidential press conferences). It also holds that uses of language can construct new rules of usage, which can construct new rules of grammar. Social systems change, and languages change, under the motor of lots of little changes in interaction. But the room for interactional manoeuvre is often very small Manny can't change the rules of court like the president can change the rules of press conferences, nor can he change the rules of English grammar (even though he may have tried to). Even if one thinks of social systems and grammar as the outcome of aeons of interactional events, at any one point they have a coercive, constraining influence on what interactants can do and what they can mean. Those constraints are best understood by treating them as systems in their own right. In that case, we are back to the working model I am trying to purvey: three independent systems hooked together by crucial intermediate variables. 
NOTES

1. The general drift of Schegloff's (1987) paper is perhaps towards the 'dangerous' interpretation. But in footnote 26 the idea is entertained that interaction, as an 'autonomous and structured field of action', plays a mediating role between 'macro' and 'micro', or between anthropology and the cognitive sciences. This view is much more in line with what I am calling the 'safe' interpretation.

2. I have been conducting fieldwork there since 1995, supported by the Max Planck Society, recently under the European Science Foundation programme 'Origin of Man, Language and Languages'.

3. All the frame grabs in this article were prepared with the ELAN multimedia annotation tool developed by the MPI for Psycholinguistics in Nijmegen, and downloadable for free from http://www.mpi.nl/tools/.

4. The version of the theory given here is actually nearer to Radcliffe-Brown's original than Lévi-Strauss's later elaboration - however, most of the differences concern relations within the kinship atom other than those focused on here (Lévi-Strauss found only one putative counterexample to the generalizations focused on here). My thanks to Jack Sidnell for insisting on precision here.

5. Consider the idea that English grammar can be reduced to the state of neurons in English speakers' heads. It has the same apparently irrefutable logic as interactional reductionism: without those neurons, there would be no English grammar. But actually, no amount of neuroanatomy is going to extract the rules of English grammar out of brain tissue (and anyway whose head should we dissect?).

\section{REFERENCES}

Armstrong, W.H. (1928) Rossel Island. Cambridge: Cambridge University Press.

Brown, P. and Levinson, S. (1987) Politeness: Universals in Language Usage. Cambridge: Cambridge University Press.

Dennett, D. (1995) Darwin's Dangerous Idea: Evolution and the Meanings of Life. London: Penguin.

Dixon, R.M.W. (1971) 'A Method of Semantic Description', in D. Steinberg and L. Jakobovits (eds) Semantics, pp. 436-71. Cambridge: Cambridge University Press.

Ford, C., Fox, B. and Thompson, S. (2002) 'Social Interaction and Grammar', in M. Tomasello (ed.) The New Psychology of Language, vol. II, pp. 119-44. Mahwah, NJ: Erlbaum.

Goffman, E. (1979) 'Footing', Semiotica 25: 1-29.

Goodwin, C. (1981) Conversational Organization. New York: Academic Press.

Goodwin, C. (ed.) (2003) Conversation and Brain Damage. Oxford: Oxford University Press.

Kendon, A. (1988) Sign Languages of Aboriginal Australia: Cultural, Semiotic and Communicative Perspectives. Cambridge: Cambridge University Press.

Levinson, S.C. (1983) Pragmatics. Cambridge: Cambridge University Press.

Levinson, S.C. (1987) 'Minimization and Conversational Inference', in M. Pappi and J. Verschueren (eds) The Pragmatic Perspective, pp. 61-129. Amsterdam: Benjamins.

Levinson, S.C. (1992) 'Activity Types and Language', in P. Drew and J. Heritage (eds) Talk at Work, pp. 66-100. Cambridge: Cambridge University Press.

Levinson, S.C. (2000) Presumptive Meanings. Cambridge, MA: MIT Press.

Levinson, S.C. (2003) Space in Language and Cognition. Cambridge: Cambridge University Press. 
Levinson, S.C. (2004) 'On the "Human Interactional Engine”, paper prepared for Wenner Gren Conference, October.

Levinson, S.C. (in preparation) 'Clans and Kinterms on Rossel Island'.

Lévi-Strauss, C. (1958) Structural Anthropology. London: Penguin Press.

Lounsbury, F. (1969) 'A Formal Account of the Crow- and Omaka-Type Kinship Terminologies', in S. Tyler (ed.) Cognitive Anthropology, pp. 212-54. New York: Holt.

Meyer Fortes, W.W. (1969) Kinship and the Social Order: The Legacy of Lewis Henry Morgan. Chicago: Aldine.

Ochs, E., Schegloff, E. and Thompson, S. (eds) (1996) Interaction and Grammar. Cambridge: Cambridge University Press.

Radcliffe-Brown, A.R. (1952) Structure and Function in Primitive Society. London: Cohen and West.

Sacks, H. (1972) 'On the Analyzability of Stories by Children', in J. Gumperz and D. Hymes (eds) Directions in Sociolinguistics, pp. 346-80. New York: Holt, Rinehart and Winston.

Sacks, H. and Schegloff, E.A. (1979) 'Two Preferences in the Organization of Reference to Persons in Conversation and their Interaction', in G. Psathas (ed.) Everyday Language, pp. 15-21. New York: Irvington.

Schegloff, E.A. (1987) 'Between Micro and Macro', in J. Alexander (ed.) The Micro-Macro Link, pp. 207-34. Los Angeles: University of California Press.

Schegloff, E.A. (1995) 'Some Practices for Referring to Persons in Talk-in-Interaction: A Partial Sketch of a Systematics', in B. Fox (ed.) Studies in Anaphora, pp. 437-85. Amsterdam: Benjamins.

Schieffelin, B. and Ochs, E. (eds) (1986) Language Socialization across Cultures. Cambridge: Cambridge University Press.

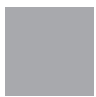

Stephen C. Levinson, University of Cambridge, BA (Archaeology, Social Anthropology), University of California Berkeley PhD (Linguistic Anthropology), has held posts at Cambridge, Stanford, and Australian National University. He is currently Director of the Max Planck Institute for Psycholinguistics, Nijmegen. He has undertaken fieldwork in India (Tamil), Mexico (Tzeltal), Australia (Guugu Yimithirr), and Papua New Guinea (Rossel). His books include Pragmatics (1983, Cambridge University Press), Politeness: Universals in Language Usage (with P. Brown, 1987, Cambridge University Press), Rethinking Linguistic Relativity (ed. with J. Gumperz, 1996, Cambridge University Press), Presumptive Meanings (2000, MIT Press), Language Acquisition and Conceptual Development (ed. with M. Bowerman, 2001, Cambridge University Press), Spatial Language and Cognition (2003, Cambridge University Press), Evolution and Culture (ed. with P. Jaisson, forthcoming, MIT Press), Grammars of Space (ed. with D. Wilkins, forthcoming, Cambridge University Press). Papers downloadable from http://www.mpi.nl/world/persons/private/ levinson/publicat.htm. ADDREss: Max Planck Institute for Psycholinguistics, PO Box 310, 6500 AH Nijmegen, The Netherlands. [email: stephen.levinson@mpi.nl] 